\title{
Crossed aphasia: a PET follow up study of two
} \section{cases}

\author{
S F Cappa, D Perani, S Bressi, E Paulesu, M Franceschi, F Fazio
}

\begin{abstract}
Two cases of aphasia after right hemispheric stroke in right handed patients are described. The first patient had a severe mixed transcortical aphasia, apraxia and neglect after a lesion involving the right lenticular nucleus and periventricular white matter; aphasia was still present after three months. The second patient had a mild, transient fluent aphasia after a small right hemispheric periventricular lesion. Studies with [18F]FDG and positron emission tomography (PET) showed functional depression extending to the structurally unaffected left hemisphere in both patients in the acute stage. After three months, in the patient with persistent aphasia, metabolism was still reduced in the right hemisphere, with some recovery of hypometabolism on the left, while metabolic values had returned to normal in the patient with full language recovery. A close parallelism between glucose metabolism and clinical course in crossed aphasia is shown, as well as the presence of a functional involvement of the structurally unaffected left hemisphere in the acute stage.
\end{abstract}

\section{$(\mathcal{F}$ Neurol Neurosurg Psychiatry 1993;56:665-671)}

Several reports of aphasia due to lesion of the right hemisphere in a right handed subject (crossed aphasia) are available in the neurological and neuropsychological literature. ${ }^{1}$ To be accepted as a genuine case of crossed aphasia, a patient must fulfil a set of restrictive criteria, to exclude any factor which could account for the exceptional case. In particular, there should not be a history of left handedness in the family, nor any associated clinical or neuroimaging evidence of lesion in the left hemisphere.

The structural integrity of the left hemisphere can be easily assessed in vivo with CT scanning or MRI. The lack of evidence for left hemispheric lesions in patients with crossed aphasia has been taken to indicate that language is localised in the right hemisphere in these patients. Neither CT scanning nor MRI, however, can exclude the presence of a left hemispheric functional impairment. Functional imaging methods, such as single photon emission computed tomography (SPECT) and positron emission tomography (PET), have been used in a handful of cases to assess regional cerebral blood flow and metabolism in patients with crossed aphasia. $^{2-4}$ However, all cases (except case 1, reference $^{4}$ ) were studied in the chronic stage. Moreover, the use of normalisation procedures to obtain indexes or interhemispheric ratios prevents the detection of any reduction of blood flow and/or metabolism in the unaffected hemisphere. Thus none of these studies provides information on the functional state of the left hemisphere in the acute or chronic stage in crossed aphasia.

We describe two cases of crossed aphasia after right hemispheric stroke in right handed patients, characterised by different clinical pictures and recovery patterns. The patients were examined both in the acute and in the chronic stage. A quantitative [18F]FDG PET examination was performed at the time of both examinations, allowing a quantitative evaluation of regional glucose metabolism in the right and left hemisphere.

\section{Material and methods PET METHOD}

For a detailed description see reference. ${ }^{5}$ [18F]FDG PET studies were performed in the resting state, with the eyes open and the ears unplugged, using a four ring whole-body PET (Siemens/CPS, 931-04/12), which gives simultaneous acquisition of data from 7 axial planes. The in plane spatial resolution of the tomograph is $6.1 \mathrm{~mm}$ full width at half maximum (FWHM). The axial spatial resolution is $6.4 \mathrm{~mm}$ FWHM. The studies were performed in a darkened, quiet room, with the patient's head resting in an individually made rigid poliurethane foam head mould, aligned to the orbito-meatal line. Acquisition protocol consists of blank and transmission scan for attenuation correction, tracer injection (250-300 MBq of [18F]FDG) followed by a rapid arterial blood sampling to obtain the arterial input function, and emission scan in the steady state condition. Forty five minutes from the tracer injection (steady state), two spatially consecutive emission scans (10 minutes each), needed to cover the whole brain, were acquired. Fourteen axial slices, parallel to the orbitomeatal lines were thus obtained. Images were reconstructed and values of local cerebral metabolic rate of glucose (LCMRG1) were calculated. ${ }^{6}$

DATA ANALYSIS

Reconstructed images were analysed on SUN (SPARC) workstations. Image processing was 
Figure 1 PET scans of case 1 in the acute post-

stroke period $(A)$ and after three months (B). See text for description and data analysis.

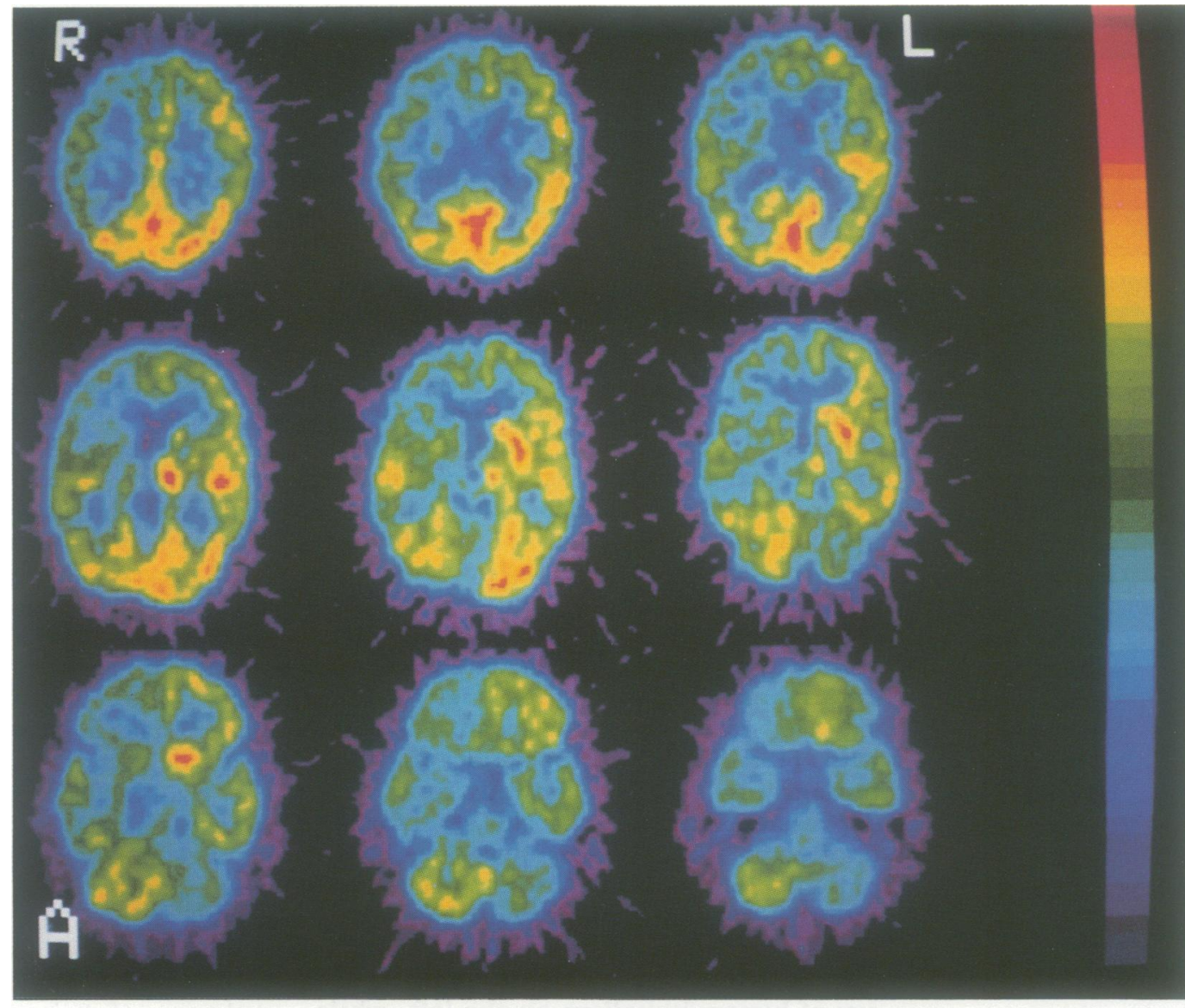



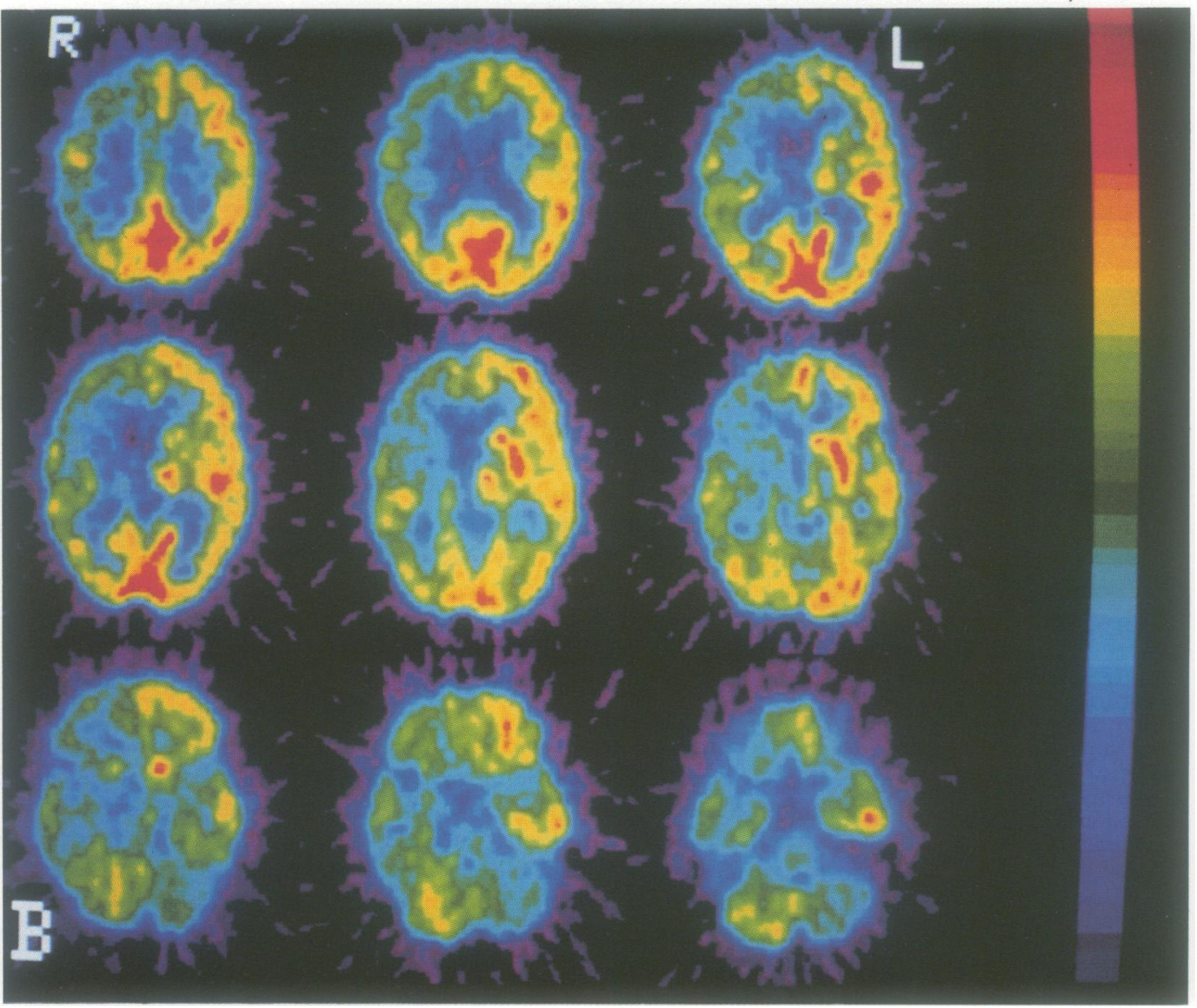


Table 1 Case 1: regional cerebral metabolic rates for glucose (LCMRGl)

\begin{tabular}{|c|c|c|c|c|}
\hline & \multicolumn{2}{|l|}{ Examination I } & \multicolumn{2}{|c|}{ Examination II } \\
\hline & Right & Left & Right & Left \\
\hline F03 & $2.52(0.28)^{\star}$ & $3.33(0.29)^{\star}$ & $3.32(0.35)^{\star}$ & $4.58(0.31)^{\star}$ \\
\hline F06 & $2.29(0.24)^{\star}$ & $3.25(0.21)^{\star}$ & $3.01(0.34)^{\star}$ & $4.75(0.34)^{\star}$ \\
\hline F07 & $2.21(0.25)^{\star}$ & $3.01(0.34)^{\star}$ & $3.01(0.36)^{\star}$ & $4.64(0.26)^{\star}$ \\
\hline F08 & $2.51(0.26)^{\star}$ & $3.38(0.26)^{\star}$ & $3.20(0.49)^{\star}$ & $4.77(0.36)^{\star}$ \\
\hline P01 & $2.50(0.29)^{\star}$ & $3.35(0.38)^{\star}$ & $3.31(0.37)^{\star}$ & $4.81(0.41)^{\star}$ \\
\hline $\mathrm{P} 02$ & $2.86(0.50)^{\star}$ & $3.76(0.32)^{\star}$ & $3.42(0.47)^{\star}$ & $4.78(0.53)^{\star}$ \\
\hline T03 & $2.72(0.57)^{\star}$ & $3.14(0.39)^{\star}$ & $3.63(0.45)^{\star}$ & $4.35(0.45)^{\star}$ \\
\hline T04 & $3.53(0.13)$ * & $4.02(0.47)^{\star}$ & $4.30(0.29)^{\star}$ & $4.72(0.29)^{\star}$ \\
\hline T07 & $3.30(0.11)^{\star}$ & $4.07(0.43)^{\star}$ & $4.06(0.22)^{\star}$ & $4.86(1.06)^{\star}$ \\
\hline T08 & $2.72(0.33)^{\star}$ & $3.02(0.27)^{\star}$ & $3.54(0.43)^{\star}$ & $4.31(0.61)^{\star}$ \\
\hline T09 & $3.15(0.56)^{\star}$ & $3.57(0.24)^{\star}$ & $4 \cdot 16(0.47)^{\star}$ & $4.93(0.34)^{\star}$ \\
\hline 001 & $3.54(0.20)^{\star}$ & $4 \cdot 28(0 \cdot 16)^{\star}$ & $5.07(0.39)^{\star}$ & $5.57(0.53)^{\star}$ \\
\hline 002 & $4.07(0.40)^{\star}$ & $4.29(0.51)^{\star}$ & $5.22(0.46)^{\star}$ & $6.31(0.32)$ \\
\hline 004 & $3.36(0.47)^{\star}$ & $4 \cdot 10(0.42)^{\star}$ & $4.68(0.28)^{\star}$ & $4.97(0.38)$ \\
\hline 005 & $3.87(0.32)^{\star}$ & $4.06(0.41)^{\star}$ & $4.64(0.47)^{\star}$ & $5.00(0.20)$ \\
\hline $\mathrm{Cau}$ & $2.39(0.20)^{\star}$ & $3.87(0.70)^{\star}$ & $1.66(0.61)^{\star}$ & $4.67(0.58)^{\star}$ \\
\hline Put & $2.73(0.14)^{\star}$ & $4.05(0.80)^{\star}$ & $2.03(0.86)^{\star}$ & $5.01(1.32)^{\star}$ \\
\hline Thal & $2.19(0.31)^{\star}$ & $4.08(0.23)^{\star}$ & $2 \cdot 16(0.55)^{\star}$ & $4.63(0 \cdot 10)^{\star}$ \\
\hline Cer & $3.41(0.23)^{\star}$ & $2 \cdot 22(0 \cdot 25)^{\star}$ & $4.32(0.37)$ & $3.72(1.10)^{\star}$ \\
\hline
\end{tabular}

LCMRGl is expressed in $\mathrm{mg} 100 \mathrm{~g}^{-1} \mathrm{~min}^{-1}$

The cerebral regions listed in the tables are labelled according to the atlas of Damasio and Damasio. ${ }^{7}$ F03: mesial supplementary motor area; F06: frontal opercolum; F07: pre-frontal regions; F08: lateral pre-motor and rolandic regions; P01: supramarginal gyrus; P02: angular gyrus; T03, T04: anterior and posterior part of middle temporal gyrus; T07: auditory region; T08, T09: superior temporal gyrus anterior and posterior to auditory region; 001, 002: infra and supra calcarine mesial occipital areas; 04, 05: inferior and superior lateral occipital regions; Cau: caudate nucleus; Put: putamen; Thal: thalamus; Cer: cerebellum.

*LCMRGl outside 2 SD from normal values performed with Analyze software (BRU/Mayo Clinic). Numerical data were obtained using circular regions of interest (ROIs) with a diameter corresponding to 1.5 FWHM. Average values of LCMRG1 were calculated for major anatomical subdivisions, making reference to an atlas. ${ }^{7}$

The averaged LCMRGI values for the same ROIs in 7 normal subjects [mean (SD) age $51.28(12.53)$, range from 36 to 73 years] were used as control values. Metabolic values in the patients were considered pathological when outside two standard deviations from corresponding values obtained in normal controls. The LCMRG1 of each patient were submitted to an analysis of variance with one between factor (acute and chronic stage) and one within factor (left and right hemisphere).

\section{Case reports}

Case 1

The patient was a 79 year old woman, right

Figure 2 Control CT scan image of case 1, showing an ischaemic lesion involving the right lenticular nucleus and periventricular white matter. There is no evidence of lesion in the lefi hemisphere. handed on the Edinburgh Inventory $(12 / 12){ }^{8}$ There was no family history of left handedness. There was a past medical history of hypertension, treated with diuretics. For several years she had experienced non-valvular atrial fibrillation, but she reported no previous neurological symptoms. She was admitted after the sudden onset of weakness of the left limbs and speech disorders. The neurological examination showed global aphasia, a left hemiplegia and hemianesthesia and a left homonymous hemianopia. CT performed the day after admission showed a hypodense lesion in the right hemisphere, involving the periventricular white matter and the lenticular nucleus. A duplex Doppler examination was indicative of occlusion of the left vertebral artery. A neuropsychological examination was performed ten days post-onset. She was found to have a severe reduction of spontaneous speech, with single-word responses to questions; speech was well articulated, but hypophonic and with a flat melodic line. Naming was severely defective (2/32 correct responses) with anomias, verbal paraphasias and perseverations. Single word comprehension was defective (19/42) and the Token test score was $9 / 36$. Repetition was relatively preserved (words $15 / 24$, sentences $11,5 / 21$, digit span 4). There was a severe alexia and agraphia. The aphasic picture would be labelled as "mixed transcortical" according to traditional taxonomy. ${ }^{9}$ Both bucco-facial and limb praxis were severely impaired. There was a clear-cut left-sided neglect on cancellation tasks and no personal neglect, while there was a partial anosognosia for motor impairment. ${ }^{10}$

The PET scan showed an extensive depression of metabolism involving subcortical structures (thalamus, basal ganglia) and frontal, temporal, parietal and occipital associative cortex in the right hemisphere. A metabolic depression, although less severe, was also present in the left hemisphere, involving in particular the frontal and parietal cortex. There was also a marked crossed cerebellar diaschisis (fig 1A). The absolute values of LCMRGl are reported in table 1. They were compared with those from seven normal controls: data below the cut-off values (mean - 2 standard deviations) are marked with an asterisk. Unfortunately, this patient was not age-matched with the control group: even if glucose metabolism has not been reported to decline significantly with normal ageing, ${ }^{11}$ the overall reduction of absolute metabolic values may be partly related to the age difference.

A follow up neuropsychological examination was performed fifteen days later: spontaneous expression was still severely impaired, with the appearance of echolalia; naming and auditory comprehension were unchanged. There was an improvement of repetition and of reading aloud. Apraxia was still severe, with some improvement of limb praxis $(15 / 72)$. Extrapersonal neglect was not evident on cancellation tasks. Three months later the patient had another neuropsychological evaluation and follow up CT and PET 
Figure 3 MR image of case 2, showing a small ischaemic lesion in the right periventricular white matter. There are no visible lesions in the left hemisphere.



scans. There was an overall improvement of language. Spontaneous speech was limited to short, syntactically correct sentences. On visual naming, there were $22 / 32$ correct responses; naming on verbal description was still severely impaired, as well as verbal fluency ( 0 responses with three phonemic cues, one minute each; 4 responses with a semantic cue, one minute each). The Token test score was 20/36. Repetition was nearly perfect. Reading aloud was good, while reading comprehension was impaired (written Token test $2 / 14$ ). Writing was severely affected, while bucco-facial and limb apraxia had substantially recovered.

The ischaemic lesion was unchanged on CT scan (fig 2). The PET scan (fig 1B) showed a substantial increase of metabolism in the frontal and parietal cortex of the right hemisphere, while the thalamus and the basal ganglia were still severely depressed. There was also an increase of cortical and subcortical left hemispheric metabolism. Crossed cerebellar diaschisis was still present

Table 2 Case 2: Regional cerebral metabolic rates for glucose (LCMRGl)

\begin{tabular}{|c|c|c|c|c|}
\hline & \multicolumn{2}{|l|}{ Examination I } & \multicolumn{2}{|c|}{ Examination II } \\
\hline & Right & Left & Right & Left \\
\hline F03 & $5.00(0.41)$ & $5 \cdot 13(0 \cdot 29)$ & $6.67(0.17)$ & $6.35(0.56)$ \\
\hline F06 & $0.31(0.49)^{\star}$ & $4.32(0.44)^{\star}$ & $6.41(0.81)$ & $6.84(0.83)$ \\
\hline F07 & $4.38(0.53)^{\star}$ & $4.54(0.47)^{\star}$ & $6 \cdot 50(0 \cdot 81)$ & $6.89(0.85)$ \\
\hline F08 & $5.16(0.56)^{\star}$ & $5.31(0.60)$ & $6.49(0.77)$ & $6.90(0.86)$ \\
\hline P01 & $4.40(0.43)^{\star}$ & $4.28(0.51)^{\star}$ & $5.91(0.43)$ & $6.11(0.69)$ \\
\hline $\mathrm{P} 02$ & $4.13(0.73)^{\star}$ & $4.44(0.48)^{\star}$ & $6.63(0.55)$ & $6.88(0.44)$ \\
\hline T03 & $4.09(0.61)^{\star}$ & $4.09(0.64)^{\star}$ & $5.23(0.30)$ & $5.00(0.76)$ \\
\hline T04 & $4 \cdot 84(0.47)^{\star}$ & $4.75(0.43)^{\star}$ & $\overline{7}$ & $\overline{-}$ \\
\hline T07 & $5.76(0.73)$ & $5.64(1.01)^{\star}$ & $7 \cdot 19(0 \cdot 85)$ & $7.60(0.43)$ \\
\hline T08 & $4.19(0.31)^{\star}$ & $4.33(0.43)^{\star}$ & $5 \cdot 13(0.57)$ & $5.00(0.33)$ \\
\hline T09 & $4.79(0.37)^{\star}$ & $4.84(0.54)^{\star}$ & $5.97(0.71)$ & $6.21(0.50)$ \\
\hline 001 & $5.86(1.08)^{\star}$ & $6.58(0.86)$ & $7 \cdot 41(1 \cdot 23)$ & $7 \cdot 15(1 \cdot 86)$ \\
\hline 004 & $5.54(0.67)$ & $5.73(0.95)$ & $5.87(0.80)$ & $6.69(0.70)$ \\
\hline 005 & $4.91(0 \cdot 16)$ & $5.38(0.30)$ & $6.46(0.51)$ & $6.63(0.61)$ \\
\hline $\mathrm{Cau}$ & $4.41(0.46)^{\star}$ & $5 \cdot 01(0.56)$ & $6 \cdot 23(0 \cdot 17)$ & $6.24(0.07)$ \\
\hline Put & $5.61(0.60)$ & $5.52(0.59)$ & $5 \cdot 51(0.58)$ & $6.35(0.64)$ \\
\hline Thal & $4.48(0.82)^{\star}$ & $5.30(0.69)$ & $5.72(0.62)$ & $6.87(0.51)$ \\
\hline Cer & $5.58(0.52)$ & $5 \cdot 16(0 \cdot 48)$ & $5 \cdot 38(0 \cdot 37)$ & $4.53(0.41)$ \\
\hline
\end{tabular}

LCMRGlc is expressed in $\mu \mathrm{g} 100 \mathrm{~g}^{-1} \mathrm{~min}^{-1}$ (table 1).

Metabolic data from the first and the second examination were analysed using ANOVA, which indicated significant differences between right and left hemisphere $(p<$ 0.0001 ) and between the first and the second examination ( $p<0.0001)$ with a significant interaction $(p=0.001)$, due to the larger recovery of left hemispheric metabolism.

\section{Case 2}

This 56 year old man with a past medical history of heavy cigarette smoking, hypertension and aortic valvulopathy was admitted after the sudden onset of language disturbances. On admission, the neurological examination was negative, except for severe word finding disturbances. The patient was strongly right handed (Edinburgh Inventory 12/12) and had no family history of left handedness. A CT scan at the time of admission was negative. MRI scan, the following day, showed a small area, with the signal characteristics of a recent ischaemic lesion, in the right periventricular region (fig 3). A four vessel angiogram was normal. A bedside language evaluation, seven days after admission, showed fluent spontaneous speech, with normal phrase length, which was characterised by frequent word finding pauses and an overall lack of cohesion and informative value. There was severe anomia on confrontation, while repetition and auditory comprehension were good. A formal evaluation nine days later showed fluent spontaneous speech, with word finding pauses and verbal paraphasias; on naming (27/32) he showed some anomias and verbal paraphasias. Single word comprehension was good for single words (65/70), while the Token test score was in the mildly impaired range (26/36). Verbal fluency was severely impaired on phonemic cues (one response in three minutes) and on semantic cues (16 responses in three minutes). Repetition and written language were normal. The patient had no evidence of neglect or bucco-facial and limb apraxia.

PET scan (four days post onset) (fig 4A) showed a mild depression in the frontal, parietal and temporal regions bilaterally, and in the right caudate and thalamus (table 2). Data below the cut-off values (mean - 2 standard deviations) of normal controls are marked with an asterisk

Follow up evaluation was performed three months later. There was an excellent linguistic recovery, with normal performance on all tests. The small ischaemic lesion in the right lateroventricular region was unchanged on a control CT. PET scan (fig 4B) showed a bilateral increase of metabolism towards normal values in the cortical and subcortical regions, with a persisting asymmetry (right $<$ left) in the putamino-thalamic region (table 2).

On ANOVA, the differences between hemispheres and between the first and the second examination were significant (respectively, $\mathrm{p}<0.0001$ and $\mathrm{p}=0.0019$ ), while the interaction was not significant. 
Figure 4 PET scans of case 2 in the acute post-

stroke period $(A)$ and after

three months $(B)$. See text

for description and data

analysis.

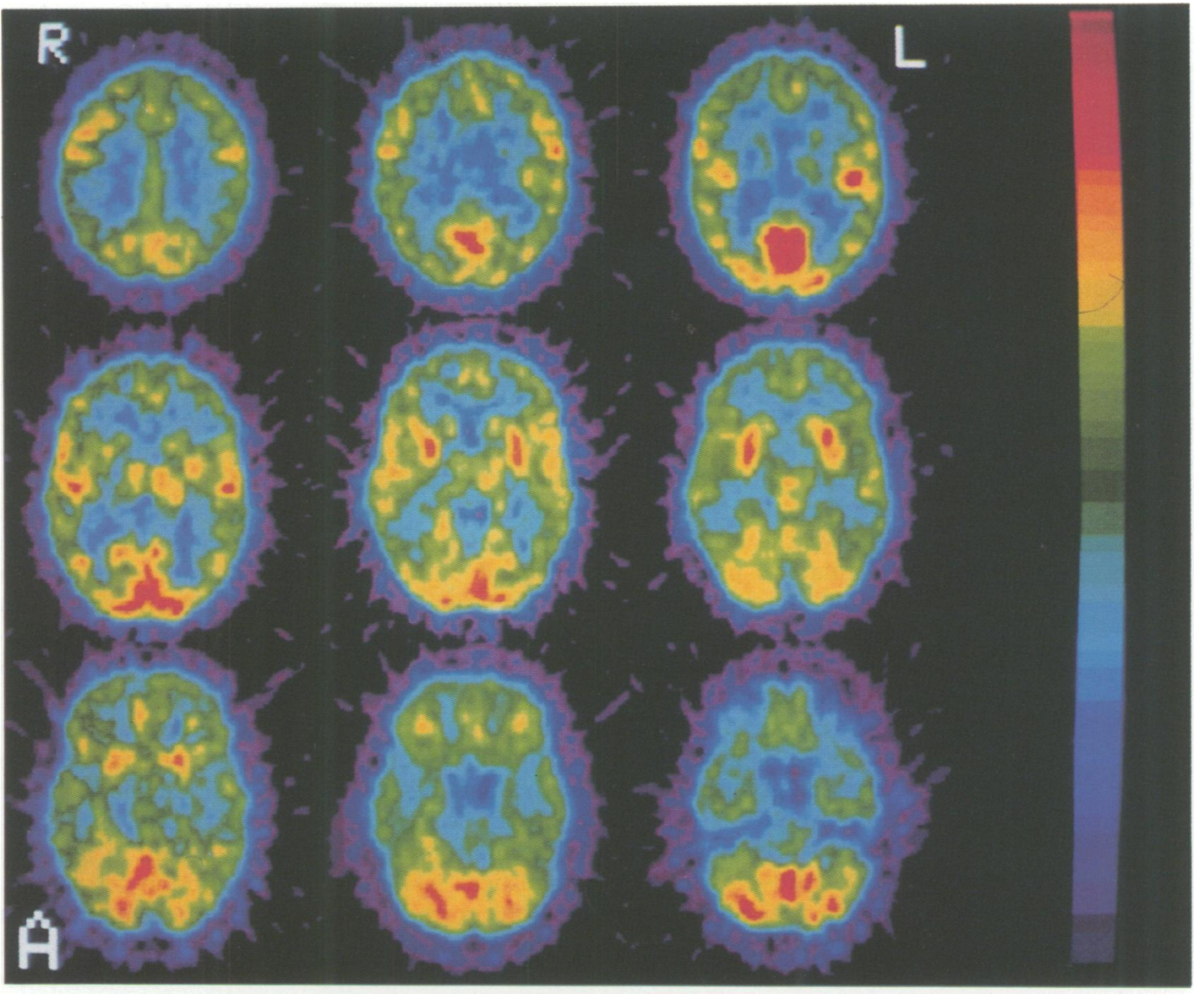

列

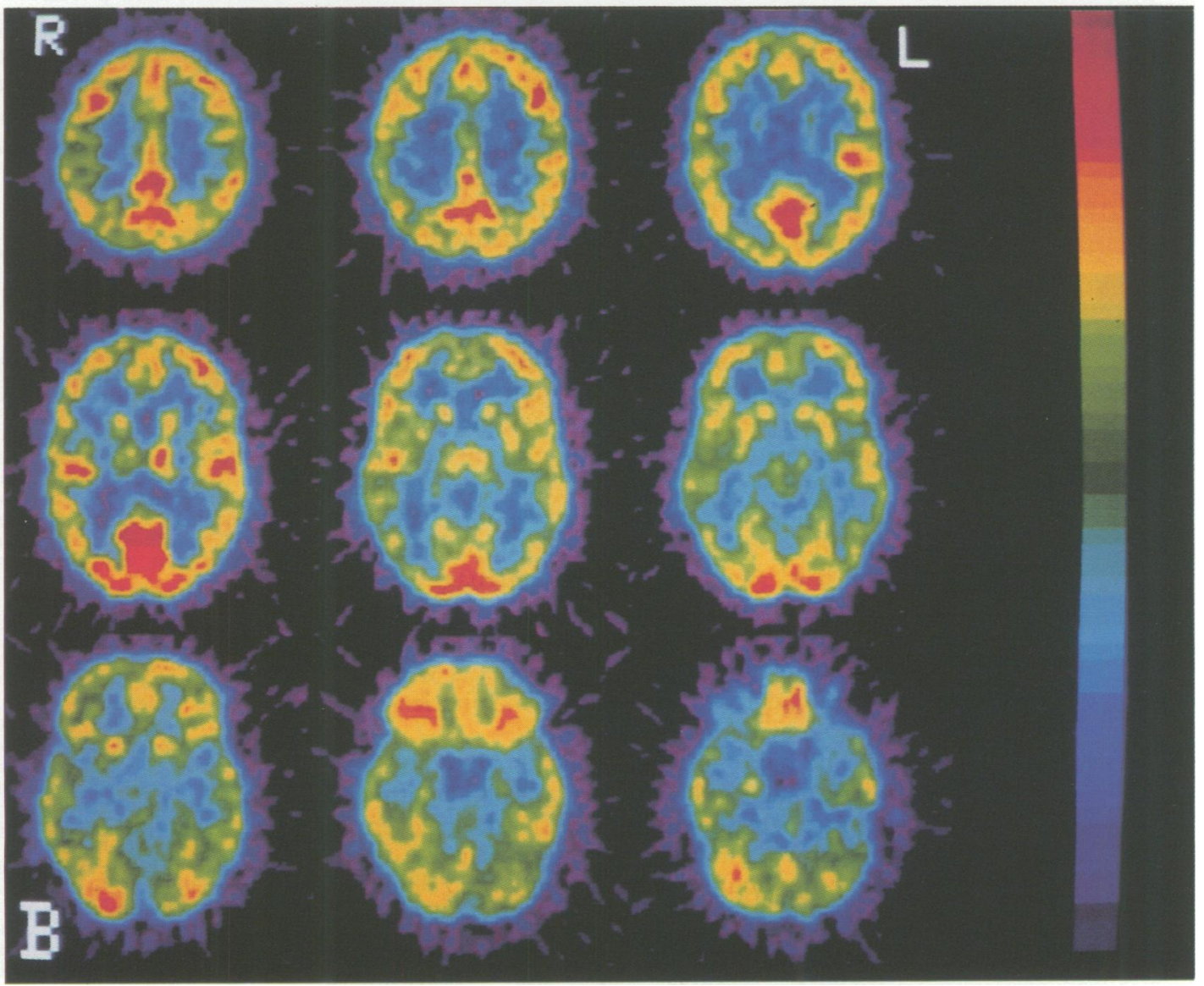




\section{Discussion}

Alexander et $a l^{12}$ have suggested a distinction between "mirror image" and "atypical" crossed aphasia: patients with "mirror" crossed aphasia are characterised by a clinical picture which would be appropriate for a lesion of similar location in the left hemisphere, while "atypical" patients display unusual symptom complexes. In the acute stage case 1 had an extremely severe mixed transcortical-type aphasia after a subcortical lesion. While similar aphasias have been reported after subcortical lesions in the left hemisphere, ${ }^{13}$ the clinical picture is usually less severe and shows faster recovery. This somewhat atypical aphasia was associated with a "mirror" sign (apraxia) as well as with a typical right hemispheric manifestation (unilateral neglect). The second patient had only a transient fluent aphasia without apraxia or neglect. A lesion of similar extent and location in the left hemisphere would be hardly expected to be associated with aphasia or other neuropsychological disorders. ${ }^{14}$

Even if there are no doubts that "cortical" crossed aphasia exists, our two patients testify the frequent occurrence of crossed aphasia after subcortical stroke. ${ }^{15}$ The main finding of our study is that the subcortical lesions in both patients were associated in the acute stage with a reduction of glucose metabolism not only in the ipsilateral, but also in the contralateral, structurally unaffected left hemisphere. The presence of depression of cerebral blood flow and metabolism in structurally unaffected cortical regions in the same hemisphere after a stroke has been associated with the occurrence of aphasia in the case of subcortical left hemispheric lesions. ${ }^{1416} \mathrm{~A}$ reduction of metabolism in the contralateral hemisphere after an acute stroke has also been reported, ${ }^{17}$ and has been attributed to transcallosal diaschisis. ${ }^{18}$

It is thus possible that in patients with crossed aphasia a dysfunction of the left hemisphere plays an important role, at least in the acute stage. Has this finding any implication for the understanding of the pattern of language lateralisation in these cases? Right hemispheric metabolic depression has been found in the acute stage also in patients with standard (left hemispheric) language lateralisation, ${ }^{19}$ and conversely, a reduction of metabolism in the left hemisphere has been found in our laboratory in patients with unilateral neglect after right hemispheric stroke and no evidence of aphasia..$^{20}$

The hypometabolism in the acute and post acute stage in the structurally unaffected hemisphere seems to be particularly severe in these two patients, suggesting that the extent of functional diaschisis may be related to development of crossed aphasia. This hypothesis, however, needs confirmation from systematic studies of the quantitative relationships between structural lesion characteristics and remote effects.

Another hypothesis is that patients with "atypical" language dominance may be more liable than patients with standard (left hemi- spheric) language dominance to show aphasia after lesions in either hemisphere: it has been reported $^{21}$ that after surgical section of the corpus callosum for the relief of epilepsy, three out of the four patients who showed language disturbances were right handed individuals with right hemispheric language dominance (that is, patients with crossed dominance) as assessed by the Wada (Amytal) test.

There is experimental evidence from animal studies ${ }^{22}$ that callosal section produces a bilateral depression of cortical metabolism: thus the bihemispheric dysfunction associated with callosotomy may cause language impairment only in this susceptible population, which could be characterised by a more "diffuse" language representation. While the participation of both hemispheres for language representation in crossed aphasic patients has been suggested, the positive evidence is not compelling: for example, in only one out of three crossed aphasic patients in which a Wada test has been performed, ${ }^{23-25}$ a worsening of aphasia was found after inactivation of the undamaged left hemisphere.

In conclusion, both cases of crossed aphasia reported in this article showed evidence of dysfunction of the structurally unaffected left hemisphere in the acute stage. These remote effects, due possibly to transcallosal diaschisis, were severe in the acute stage in both patients, and persisted in the case with poor recovery. Patients with "atypical" language dominance may be particularly liable to the functional consequences of an unilateral stroke, suggesting a more "diffuse", bihemispheric representation of language in patients with crossed aphasia.

1 Faglia L, Rottoli MR, Vignolo LA. Aphasia due to lesions confined to the right hemisphere in right handed patients: a review of the literature including the Italian cases. Italian fournal of Neurological Sciences 1990;11: cases. Itali 44 .

2 Schweiger A, Wechsler AF, Mazziotta JC. Metabolic correlates of linguistic functions in a patient with crossed

3 Walker-Batson D, Wendt JS, Devous Sr MD, Barton MM, Bonte FJ. A long term follow up case study of crossed aphasia assessed by Single-Photon Emission Tomography (SPECT), language and neuropsychological testing. Brain Language 1988;33:31 1-22.

4 Perani D, Papagno C, Cappa SF, Gerundini P, Fazio F. Crossed aphasia: functional studies with single photon emission computerized tomography. Cortex 1988;24: 171-8.

5 Fazio F, Perani D, Gilardi MC, et al. Metabolic impairment in human amnesia: a PET study of memory networks. Cereb Blood Flow Metab 1992;12:353-8.

6 Reivich M, Alavi A, Wolf A, et al. Glucose metabolic rate kinetic model parameter determination in humans: the lumped constants and rate constants for $18 \mathrm{~F}$-fluorodeoxyglucose and 11C-deoxyglucose.) Cereb Blood rodeoxyglucose and 11C-d

7 Damasio H, Damasio A. Lesion analysis in neuropsychology. New York: Oxford University Press, 1989.

8 Oldfield RC. The assessment and analysis of handedness. Neuropsychologia 1971;9:97-113.

9 Goodglass $\mathrm{H}$, Kaplan $\mathrm{E}$. The assessment of aphasia and related disorders. Philadelphia: Lea and Febiger 1972.

10 Bisiach E, Vallar G, Perani D, Papagno C, Berti A. Unawareness of disease following lesions of the right hemisphere: anosognosia for hemiplegia and anosognosia for hemianopia. Neuropsychologia 1986;24:471-82.

1 De Leon MJ, George AE, Ferris SH, et al. Positron emission tomography and computed tomography assesssion tomography and computed tomography assessTomography 1984;8:88-94.

12 Alexander MP, Fischette MR, Fisher RS. Crossed aphasia can be mirror image or anomalous. Case reports, review can be mirror image or anomalous. Case

13 Cappa SF, Vignolo LA Transcortical features of aphasia following left thalamic hemorrhage. Cortex 1979; 
15:121-9.

14 Skyhoj Olsen T, Bruhn P, Oeberg RGE. Cortical hypoperfusion as a possible cause of subcortical aphasia. Brain 1986;109:393-410.

15 Habib M, Joannette Y, Ali-Cherif A, Poncet M. Crossed aphasia in dextral: a case report with special reference to site of lesion. Neuropsychologia 1983;21:413-18.

16 Perani D, Vallar G, Cappa SF, Messa C, Fazio F. Aphasia and neglect after subcortical stroke. Brain 1987;110: 1211-29.

17 Baron JC, D'Antona R, Pantano P, Serdaru M, Samson Y, Bousser MG. Effects of thalamic stroke on energy metabolism of the cerebral cortex. Brain 1986;109: 1243-59.

18 Dobkin JA, Levine RL, Lagreze HL, Dulli DA, Nickles RJ, Rowe BR. Evidence for transhemispheric diaschisis in unilateral stroke. Arch Neurol 1989;46:1333-6.

19 Cappa SF, Perani D, Vallar G, et al. Recovery from aphasia after acute stroke. A PET metabolic follow-up study. Neurology 1991;41(Suppl 1):369.
20 Perani D, Vallar G, Paulesu E, et al. Left and right hemisphere contribution to recovery from neglect after right sphere contribution to recovery from neglect after right hemisphere damage. A [18F] FDG PE

21 Sass KJ, Novelly RA, Spencer DD, Spencer SS Postcallosotomy language impairments in patients with crossed cerebral dominance. If Neurosurg 1990;72: 85-90.

22 Yamaguchi T, Kunimoto M, Pappata S, et al. Effects of anterior corpus callosum section on cortical glucose utilization in baboons. Brain 1990;113:937-51.

23 Angelergues $R$, Hecaen $H$, Djndjian $R$, Jarrié-Hazan $N$. Un cas d'aphasie croisée (thrombose de l'artère sylvienne droite chez une droitière). Revue Neurologique 1962;107:543-56.

24 Delreux V, de Partz MP, Kevers L, Callewaert A. Aphasie croisée chez un droitier. Revue Neurologique 1989;145: croisée

25 Zangwill OL. Two cases of crossed aphasia in dextrals. Neuropsychologia 1979;17:167-72. 